\title{
STRATEGI MENINGKATKAN LOYALITAS DENGAN MEMPERHATIKAN KEPUASAN KONSUMEN OBAT MELALUI COORPORATE IMAGE PADA APOTEK DI SURAKARTA
}

\author{
Siti Fatonah ${ }^{1}$, I Gusti Putu Diva Awatara ${ }^{2}$ \\ ${ }^{1,2}$ Program Studi S2 - Manajemen STIE AUB Surakarta \\ Email: siti.fatonah@stie-aub.ac.id
}

\begin{abstract}
This study discusses strategies for increasing drug consumer loyalty by paying attention to satisfaction using aspects of service quality, order delivery and promotion that can be referred to as a corporate image at a pharmacy in Surakarta. This study is to find out how and how much influence the independent variable (service quality, delivery of orders, promotions) on drug consumer loyalty with satisfaction as an intervening variable so that it can be used to determine the strategy that must be carried out by pharmacies in Surakarta. By taking a sample of 100 respondents drug consumers randomly taken at several pharmacies located in Surakarta. After processing the path analysis, the results show that order delivery dominates to increase drug consumer satisfaction compared to service quality and promotion. To increase loyalty based on the results of the analysis, it is necessary to increase the satisfaction of drug consumers first because all independent variables do not have a significant direct effect on loyalty. For this reason, it was concluded that the strategy to increase drug consumer loyalty in Surakarta pharmacies should be pharmacies to increase order delivery services to increase satisfaction that is expected to increase drug consumer loyalty to pharmacies in Surakarta.
\end{abstract}

Keywords: Service Quality, Order Delivery, Promotion, Satisfaction, Loyalty and Medicine

Penelitian ini membahas tentang strategi untuk meningkatkan loyalitas konsumen obat dengan memperhatikan kepuasan yang menggunakan aspek kualitas pelayanan, pengiriman pesanan dan promosi yang bisa disebut sebagai coorporate image pada apotek di Surakarta. Penelitian ini untuk mengetahui bagaimana dan seberapa besar pengaruh variabel independen (kualitas pelayanan, pengiriman pesanan, promosi) terhadap loyalitas konsumen obat dengan kepuasan sebagai variabel intervening sehingga dapat digunakan untuk menentukan strategi yang harus dilakukan apotek di Surakarta. Dengan mengambil sample sebanyak 100 responden konsumen obat yang diambil secara acak di beberapa apotek yang berlokasi di Surakarta. Setelah di olah dengan analisis jalur, diperoleh hasil bahwa pengiriman pesanan mendominasi untuk meningkatkan kepuasan konsumen obat dibandingkan dengan kualitas pelayanan dan promosi. Untuk meningkatkan loyalitas berdasarkan hasil analisis maka harus meningkatkan kepuasan konsumen obat terlebih dahulu karena semua variabel independen secara langsung berpengaruh tidak signifikan terhadap loyalitas. Untuk itu disimpulkan bahwa strategi untuk meningkatkan loyalitas konsumen obat di apotek Surakarta sebaiknya apotek meningkatkan pelayanan pengiriman pesanan untuk meningkatkan kepuasan yang diharapkan dapat meningkatkan loyalitas konsumen obat terhadap apotek di Surakarta.

Kata Kunci: Kualitas Pelayanan, Pengiriman Pesanan, Promosi, Kepuasan, Loyalitas dan Obat

(c) 2019 JBTI. All rights reserved

Article History : Received: 2019-11-23; Revised: 2019-11-23; Accepted: 2019-12-28

\section{PENDAHULUAN}

Sehat adalah harapan bagi semua masyarakat, karena itu semua masyarakat mau menjadi konsumen obat untuk memenuhi kebutuhan akan kesehatannya. Hal ini harus diimbangi oleh 
produsen obat untuk memberikan kepuasan konsumen agar menjadi konsumen yang potensial. Instansi yang diberi izin secara formal untuk menjual belikan obat adalah apotek.

Menurut Peraturan Menteri Kesehatan RI nomor 35 tahun 2014, apotek adalah sarana pelayanan kefarmasian tempat dilakukan praktik kefarmasian oleh Apoteker. Berhubungan dengan hal tersebut, arti dari pelayanan kefarmasian adalah suatu pelayanan langsung dan bertanggung jawab kepada pasien yang berkaitan dengan kesediaan farmasi dengan maksud mencapai hasil yang pasti untuk meningkatkan mutu kehidupan pasien. Dengan demikian, pelayanan kefarmasian yang baik sangat dibutuhkan masyarakat untuk menjaga dan meningkatkan kualitas kesehatan masyarakat.

Apotek merupakan garis terdepan dari rantai pasok industri farmasi yang dikenal olah masyarakat luas. Di Indonesia, lebih dari $24 \%$ obat yang diproduksi oleh industri farmasi didistribusikan di apotek (Sampurno, 2011). Pertumbuhan jumlah apotek tiap tahun juga makin pesat. Hal ini disebabkan karena semakin besarnya jumlah penduduk Indonesia dan masalah kesehatan yang semakin kompleks.

Pelayanan farmasi di apotek saat ini telah bergeser dari pelayanan produk atau obat (drug oriented) menjadi pelayan pasien (patient oriented) (Ihsan et al.2014). Kegiatan pelayanan yang tadinya hanya berfokus pada pengelolaan obat sebagai komoditi berubah menjadi pelayanan yang komprehensif dengan tujuan untuk meningkatkan kualitas hidup pasien.

Fenomena ini bisa dilihat pada transaksi obat di apotek, apotek tidak hanya melayani resep, namum juga menjual obat secara langsung kepada masyarakat yang membutuhkan bahkan di beberapa apotek adapegawainya berprofesi sebagai dokter prakter pada apotek tersebut.

Keberlangsungan bisnis apotek salah satunya ditentukan oleh kepuasan konsumen. Kepuasan konsumen berkaitan erat dengan kualitas pelayanan. Kepuasan konsumen didapatkan jika apa yang dirasakan konsumen dari suatu pelayanan sebanding atau lebih besar dari harapan mereka (Kotler dan Keller, 2012). Pelayanan obat yang tepat dan berkinerja baik akan berpengaruh terhadap peningkatan kesehatan mayarakat yang utuh. Masyarakat pun semakin kritis memilih pelayanan farmasi. Apabila pelayanan berkualitas maka akan terwujud pula masyarakat yang berkualitas. pelayanan yang berkualitas artinya secara coorporate bisa memenuhi harapan konsumen.

Pada dasarnya apotek didirikan dengan tujuan agar dapat memberikan pelayanan farmasi yang baik kepada masyarakat termasuk siap memberikan konsultasi obat, penyediaan obat dan perbekalan farmasi dengan mutu yang baik. Oleh karena itu apotek perlu melakukan inovasi dalam melakukan kegiatan promosi untuk memberikan informasi dan menarik masyarakat untuk mau membeli dan menjadi konsumen obat yang loyal. Salah satu faktor penting yang mempengaruhi berkembangnya suatu apotek yaitu bagaimana apotek dapat memberikan kemudahan kepada konsumen untuk memesan obat dan menerima barang (obat) dengan mudah, cepat, aman dan nyaman.

Dengan kemajuan teknologi, perkembangan komunikasi pun mengikuti untuk masuk ke Revolusi Industri 4.0. Maka disini apotek mempunyai peluang bisnis untuk lebih bisa meningkatkan kepuasan konsumennya melalui pemesanan dan penerimaan pemesanan resep obat melalui layanan call center atau layanan pesan antar. Hal ini bertujuan untuk meningkatkan loyalitas para konsumen. Ini dibuktikan dengan penelitian Wang I-Ming dkk (2016), Rista (2017) dan Agung (2019) menyatakan bahwa kualitas pelayanan berpengaruh signifikan terhadap loyalitas konsumen. Hasil tersebut berbeda dengan hasil penelitian Romadhon (2016) yang menyatakan bahwa kualitas pelayanan berpengaruh tidak signifikan terhadap loyalitas. Pada hasil penelitian Rista (2017) menunjukkan bahwa promosi berpengaruh tidak signifikan terhadap loyalitas. Hasil tersebut berkebalikan dengan penelitian Maharsi (2016) yang menunjukkan bahwa promosi berpengaruh signifikan terhadap loyalitas. 
Dengan memperhatikan fenomena dan hasil empiris tersebut, maka peneliti mengambil judul "Strategi Meningkatkan Loyalitas dengan Memperhatikan Kepuasan Konsumen Obat melalui Coorporate Image Pada Apotek Di Surakarta”.

\section{METODE PENELITIAN}

Penelitian ini menggunakan random sampling dimana seluruh anggota populasi mempunyai kesempatan yang sama sebagai sampel. Peneliti mengambil sampel sebanyak 100 responden yang merupakan konsumen obat di apotek Surakarta. Uji instrumen dalam penelitian ini menggunakan uji validitas dan uji reliabilitas. Model uji analisis dengan menggunakan analisa jalur dengan variabel kepuasan sebagai variabel intervening untuk variabel independen (Kualitas Pelayanan, Pengiriman Pesanan dan Promosi) terhadap variabel dependen (Loyalitas).

Persamaan pada penelitian ini terdiri dari 2 persamaan yaitu :

$$
\begin{aligned}
& \mathrm{Y} 1=\beta 1 \mathrm{X} 1+\beta 2 \mathrm{X} 2+\beta 3 \mathrm{X} 3+\mathrm{e} \ldots \ldots \ldots \ldots \\
& \mathrm{Y} 2=\beta 4 \mathrm{X} 1+\beta 5 \mathrm{X} 2+\beta 6 \mathrm{X} 3+\beta 7 \mathrm{Y} 1+\mathrm{e} .
\end{aligned}
$$

Ket:

$$
\begin{array}{ll}
\text { X4/Y1 } & =\text { Kepuasan } \\
\text { Y2 } & =\text { Loyalitas } \\
\text { X1 } & =\text { Kualitas Pelayanan } \\
\text { X2 } & =\text { Pengiriman Pesanan } \\
\text { X3 } & =\text { Promosi } \\
€ 1 & =\text { Residual } \\
\mathrm{B} & =\text { Koefisien }
\end{array}
$$

\section{HASIL PENELITIAN DAN PEMBAHASAN}

Berdasarkan hasil analisa jalur dapat diperoleh hasil sebagai berikut :

$$
\begin{aligned}
\text { 1. } Y_{1}= & \beta_{1} X_{1}+\beta_{2} X_{2}+\beta_{3} X_{3}+e \\
= & 0,440 X_{1}+0,473 X_{2}+0,119 X_{3}+e \\
(0,000)(0,000) & (0,213)
\end{aligned}
$$

2. $Y_{2}=\beta_{4} X_{1}+\beta_{5} X_{2}+\beta_{6} X_{3}+\beta_{7} Y_{1}+e$

$$
\begin{gathered}
=0,235 \mathrm{X}_{1}+0,217 \mathrm{X}_{2}+0,177 \mathrm{X}_{3}+0,401 \mathrm{Y}_{1}+\mathrm{e} \\
(0,156)(0,310) \quad(0,219) \quad(0,000)
\end{gathered}
$$




\section{Model Hasil Analisis:}

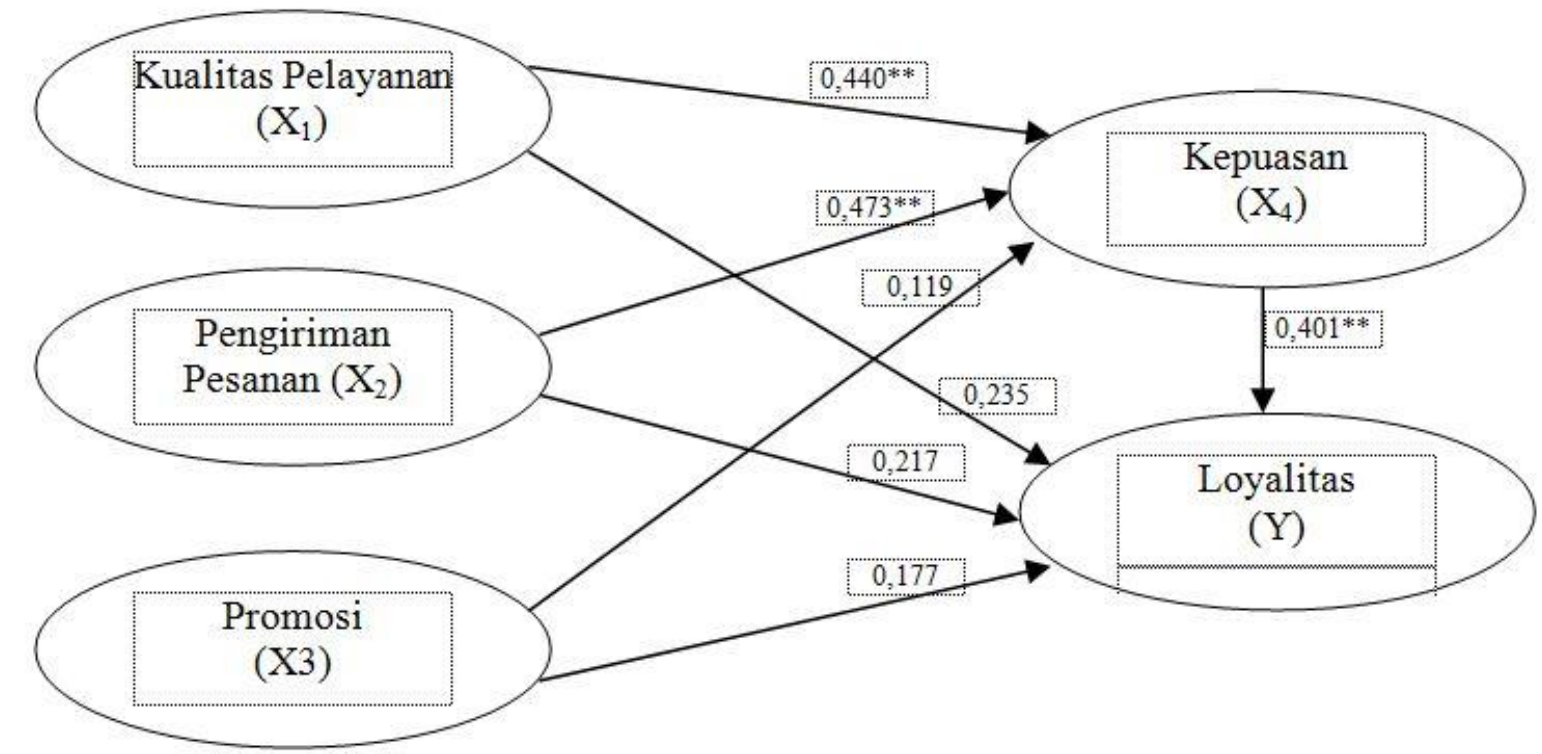

Gambar 1. Hasil Diagram Analisis Jalur

Kerangka konseptual ini terdiri dari 2 persamaan yaitu :

1. Hasil Persamaan 1

$\mathrm{Y}_{1}=\beta_{1} \mathrm{X}_{1}+\beta_{2} \mathrm{X}_{2}+\beta_{3} \mathrm{X}_{3}+\mathrm{e}$ dengan hasil :

a. Kepuasan = 0,440 Kualitas Pelayanan + 0, 473 Pengiriman Pesanan + 0,119 Promosi

b. Kualitas pelayanan, pengiriman pesanan dan promosi berpengaruh positif terhadap kepuasan.

c. Jika kualitas pelayanan ditingkatkan, pengiriman pesanan dijamin dan ditingkatkan kualitasnya serta promosi digencarkan maka kepuasan konsumen obat akan semakin meningkat.

d. Kualitas pelayanan dan pengiriman pesanan berpengaruh signifikan terhadap kepuasan, tetapi promosi berpengaruh tidak signifikan terhadap kepuasan konsumen obat. (Lihat pada tabel Uji hipotesis)

e. Dari persamaan didapat hasil bahwa strategi untuk meningkatkan kepuasan konsumen obat yang paling efektif dengan lebih meningkatkan pengiriman pesanan.

2. Hasil Persamaan 2

$Y_{2}=\beta_{4} X_{1}+\beta_{5} X_{2}+\beta_{6} X_{3}+\beta_{7} Y_{1}+e$ dengan hasil :

a. Loyalitas $=0,235$ Kualitas Pelayanan + 0,217 Pengiriman Pesanan + 0,177 Promosi + 0,401 Promosi

b. Kualitas pelayanan, pengiriman pesanan, promosi dan kepuasan mempunyai pengaruh positif terhadap loyalitas. Yang artinya jika kualitas pelayanan, pengiriman pesanan dan promosi serta kepuasan semuanya ditingkatkan akan mengakibatkan naiknya loyalitas konsumen obat.

c. Dari hasil olahan bahwa untuk meningkatkan loyalitas konsumen obat harus mempertimbangkan 4 variabel diatas, tetapi varibel kepuasan konsumen obat lah yang paling perlu ditingkatkan karena merupakan satu-satunya variabel yang mempunyai pengaruh positif dan signifikan terhadap loyalitas konsumen. (Lihat pada tabel Uji hipotesis) 
d. Dari persamaan didapat hasil bahwa variabel kepuasan harus paling perlu ditingkatkan karena merupakan yang paling efektif untuk menaikkan loyalitas konsumen dan baik sebagai variabel intervening.

3. Strategi untuk meningkatkan loyalitassebaiknya meningkatkan kepuasan dengan memperhatikan aspek pengiriman pesanan untuk tetap ditingkatkan.

\section{Uji Hipotesis}

\begin{tabular}{lccl}
\hline \multicolumn{1}{c}{ Hubungan Antar } & Beta & Sig & \multicolumn{1}{c}{ Keterangan } \\
\hline $\mathrm{X}_{1} \rightarrow \mathrm{Y}_{1}$ & 0,440 & 0,000 & $\mathrm{H}_{1}$. Terbukti \\
\hline $\mathrm{X}_{2} \rightarrow \mathrm{Y}_{1}$ & 0,473 & 0,000 & $\mathrm{H}_{2}$. Terbukti \\
\hline $\mathrm{X}_{3} \rightarrow \mathrm{Y}_{1}$ & 0,119 & 0,213 & $\mathrm{H}_{3}$. Tidak Terbukti \\
\hline $\mathrm{X}_{1} \rightarrow \mathrm{Y}_{2}$ & 0,235 & 0,156 & $\mathrm{H}_{4}$. Tidak Terbukti \\
\hline $\mathrm{X}_{2} \rightarrow \mathrm{Y}_{2}$ & 0,217 & 0,310 & $\mathrm{H}_{5}$. Tidak Terbukti \\
\hline $\mathrm{X}_{3} \rightarrow \mathrm{Y}_{2}$ & 0,177 & 0,219 & $\mathrm{H}_{6}$. Tidak Terbukti \\
\hline $\mathrm{Y}_{1} \rightarrow \mathrm{Y}_{2}$ & 0,401 & 0,000 & $\mathrm{H}_{7}$ Terbukti \\
\hline
\end{tabular}

Pengaruh Langsung Dan Pengaruh Tidak Langsung

\begin{tabular}{llll}
\hline No & Hubungan Antar Variabel & Pengaruh Langsung & Pengaruh Tak langsung \\
\hline 1 & Kualitas Pelayanan $\rightarrow$ Loyalitas & 0,235 & \\
\hline 2 & Pengiriman Pesanan $\rightarrow$ Loyalitas & 0,217 & \\
\hline 3 & Promosi $\rightarrow$ Loyalitas & 0,177 & $0,440^{* *} \times 0,401^{* *}=$ \\
\hline 4 & $\begin{array}{l}\text { Kualitas Pelayanan } \rightarrow \text { Kepuasan } \rightarrow \\
\text { Loyalitas }\end{array}$ & & $0,176^{* *}$ \\
\hline 5 & $\begin{array}{l}\text { Pengiriman Pesanan } \rightarrow \text { Kepuasan } \rightarrow \\
\text { Loyalitas }\end{array}$ & $0,473^{* *} \times 0,401^{* *}=$ \\
\hline 6 & Promosi $\rightarrow$ Kepuasan $\rightarrow$ Loyalitas & $0,1190^{* *} \times 0,401^{* *}=0,048^{*}$ \\
\hline
\end{tabular}

Hasil :

- Hasil pengaruh langsung variable kualitas pelayanan, variabel pengiriman pesanan dan variabel promosi terhadap variabel loyalitas adalah tidak signifikan .

- Maka sebaiknya semua variabel independen untuk meningkatkan loyalitas melalui variabel kepuasan konsumen.

- Untuk meningkatkan loyalitas yang paling efektif adalam melalui variabel pengiriman pesanan sebagai variable independen.

\section{PEMBAHASAN}

1. Pengaruh kualitas pelayanan terhadap loyalitas melalui kepuasan konsumen obat.

Dari analisis jalur menunjukkan bahwa kualitas pelayanan berpengaruh tidak signifikan terhadap loyalitas. Kualitas pelayanan berpengaruh positif dan signifikan terhadap kepuasan konsumen obat. 
Hasil ini mendukung penelitian Rista (2017) dan Agung (2019). Hasil ini digunakan sebagai dasar untuk membuat strategi peningkatan loyalitas yang menggunakan variabel independen beruapa variabel kualitas pelayanan, hendaknya harus memuaskan konsumen terlebih dahulu , baru setelah itu akan berdampak pada peningkatan loyalitas konsumen.

Variabel pelayanan yang bisa meningkatkan kepuasan konsumen, antara lain :

a. Apotek di Surakarta selalu meningkatkan dan menjaga fasilitas fisik, perlengkapan, sarana dan prasarana agar selalu sesuai standar.

b. Pegawai apotek di Surakarta selalu meningkatkan keandalan dalam pelayanan (Reliability) dan memberikan informasi yang akurat.

c. Pegawai apotek di Surakarta selalu meningkatkan dalam berpenampilan didepan konsumen dan selalu berempati dan bertutur dengan baik.

d. Apotek di Surakarta hendaknya selalu meningkatkan jaminan akan pelayanan dan harga yang bersaing dengan apotek lainnya.

e. Apotek di Surakarta hendaknya selalu menjaminan kerersediaan dan kelengkapan obat yang dibutuhkan konsumen.

Sedangkan variabel kepuasan yang bisa meningkatkan kualitas pelayanan adalah:

a. Konsumen puas dengan fasilitas yang ada di Apotek

b. Konsumen puas dengan pelayanan dan informasi yang diberikan petugas Apotek

c. Konsumen puas dengan sikap dan penampilan para petugas Apotek

d. Konsumen puas dengan harga obat yang diberikan oleh apotek.

e. Konsumen puas dengan ketersediaan kebutuhan obat - obatan di apotek.

2. Pengaruh pengiriman pesanan terhadap loyalitas melalui kepuasan konsumen obat.

Variabel pengiriman pesanan berpengaruh positif tetapi tidak signifikan terhadap loyalitas. Hasil ini didukung dengan hasil penelitian Agung (2019). Sedangkan variabel pengiriman pesanan berpengaruh positif dan signifikan terhadap kepuasan konsumen obat, didukung dengan penelitian Agung (2019).

Hasil pengaruh langsung lebih besar tetapi tidak signifikan bila dibandingkan dengan pengaruh tidak langsung. Sehingga strategi untuk meningkatkan loyalitas konsumen obat di apotek Surakarta sebaiknya menggunakan strategi meningkatkan kualitas pengiriman pesanan untuk meningkatkan kepuasan konsumen obat.

Kualitas pengiriman pesanan untuk meningkatkan kepuasan konsumen obat, dapat ditempuh dengan cara, antara lain :

a. Apotek di Surakarta menyediakan layanan call center pengiriman pesanan mudah untuk dihubungi.

b. Petugas call center pengiriman pesanan pada apotek di Surakarta cekatan dan teliti dalam menerima pesanan obat.

c. Petugas pengiriman pesanan pada apotek di Surakarta bersikap dan berpenampilan rapi dan sopan.

d. Kesesuaian dan kerapihan petugas apotek dalam pengepakan pesanan obat yang dikirim.

e. Petugas pengiriman pada apotek di Surakarta tepat waktu dalam pengiriman pesanan obat.

Sedangkan kepuasan konsumen obat untuk meningkatkan loyalitas dapat ditempuh melalui :

a. Konsumen puas dengan fasilitas yang ada di Apotek

b. Konsumen puas dengan pelayanan dan informasi yang diberikan petugas Apotek

c. Konsumen puas dengan sikap dan penampilan para petugas Apotek

d. Konsumen puas dengan harga obat yang diberikan oleh apotek.

e. Konsumen puas dengan ketersediaan kebutuhan obat - obatan di apotek. 


\section{Pengaruh promosi terhadap loyalitas melalui kepuasan konsumen obat pada apotek di} Surakarta.

Promosi berpengaruh positif tetapi tidak signifikan terhadap loyalitas. Hasil ini mendukung penetilian Jurnal Rista (2017).

Promosi juga berpengaruh positif tetapi tidak signifikan terhadap kepuasan konsumen obat. Hasil ini mendukung penetilian Jurnal Rista (2017).

Namun kepuasan berpengaruh positif dan signifikan terhadap loyalitas pada apotek di Surakarta. Hasil ini mendukung penelitian Rista (2017) dan Agung (2019).

Dari hasil diatas bahwa jika variabel promosi tetap dipakai maka harus melalui kepuasan terlebih dahulu, karena kepuasan berpengaruh signifikan terhadap loyalitas pada apotek di Surakarta.

Untuk itu ada upaya promosi yang harus dilakukan sebagai berikut :

a. Layout dan display penataan obat di etalase apotek harus menarik untuk dilihat oleh konsumen.

b. Baliho dan leaflet yang dikeluarkan oleh apotek harus memperlihatkan identitas apotek.

c. Alat promosi yang dipakai apotek harus berpengaruh untuk menarik minat konsumen baru.

d. Harga obat yang diberlakukan diusahakan relatife lebih murah dibanding dengan apotek yang sejenis.

e. Apotek mengadakan pengobatan gratis untuk menjaring konsumen yang potensial.

Dari hasil tiga (3) analisis variabel independen yatitu kualitas pelayanan, pengiriman pesanan dan promosi diperoleh bahwa variabel pengiriman pesanan yang harus diperhatikan atau ditingkatkan untuk meningkatkan loyalitas melaui kepuasan.

\section{KESIMPULAN DAN SARAN}

Berdasarkan hasil analisis dan pembahasan maka selanjutnya dapat ditarik kesimpulan sebagai berikut:

1. Dari tujuh (7) hipotesis dalam penelitian ini, hanya terdapat tiga (3) yang terbukti, yaitu :

$\mathrm{H}_{1}=$ kualitas pelayanan berpengaruh positif dan signifikan terhadap kepuasan konsumen obat. $\left(\beta_{1}=0,440\right.$, Sig $\left.=0,000\right)$

$\mathrm{H}_{2}$ = pengiriman pesanan berpengaruh positif dan signifikan terhadap kepuasan konsumen obat. $\left(\beta_{2}=0,473\right.$, Sig $\left.=0,000\right)$

$\mathrm{H}_{7}=$ kepuasan berpengaruh positif dan signifikan terhadap loyalitas.

$\left(\beta_{7}=0,401\right.$, Sig $\left.=0,000\right)$

2. Empat (4) hipotesis yang tidak terbukti, yaitu :

$\mathrm{H}_{3}=$ promosi berpengaruh positif dan tidak signifikan terhadap kepuasan konsumen obat. $\left(\beta_{3}=0,119\right.$, Sig $\left.=0,213\right)$

$\mathrm{H}_{4}=$ kualitas pelayanan berpengaruh positif dan tidak signifikan terhadap kepuasan konsumen obat.

$$
\left(\beta_{4}=0,235, \operatorname{Sig}=0,156\right)
$$

$\mathrm{H}_{5}=$ pengiriman pesanan berpengaruh positif dan tidak signifikan terhadap loyalitas.

$\left(\beta_{5}=0,217\right.$, Sig $\left.=0,310\right)$

$\mathrm{H}_{6}=$ promosi berpengaruh positif dan tidak signifikan terhadap loyalitas.

$\left(\beta_{6}=0,177\right.$, Sig $\left.=0,215\right)$

Hasil analisis jalur menunjukkan bahwa variabel independen kepuasan sangat efektif digunakan untuk meningkatkan loyalitas konsumen obat pada apotek di Surakarta. 


\section{DAFTAR PUSTAKA}

Arikunto, Suharsimi. 2012. Prosedur Penelitian: Suatu Pendekatan Praktek, Jakarta : Rineka Cipta.

Ghozali, Imam. 2006. Aplikasi Analisis Multivariat dengan Program SPSS (Edisi : ke 4). Semarang : Badan Penerbit Undip.

Ghozali, Imam. 2011. Analisis Multivariat. Semarang : Badan Penerbit Undip.

Griffin, Jill. 2014. Customer Loyalty : Menumbuhkan Dan Mempertahankan Pelanggan. Jakarta : Airlangga.

H.J. Astuti dan K Nagase, 2014. Petient Loyalty to Healthcare Organization: Relationship Marketing and Satisfaction, International Journal and Marketing Research , Vol 7, No.2,2014, p.39-56

Juanim, 2004. Analisis Jalur dalam Riset Pemasaran Bandung : Fakultas Ekonomi, UPAS.

Karsono, 2005. Peran Perpindahan Yang Memediasi Pengaruh Kualitas Pelayanan Terhadap Loyalitas Pelanggan, Jurnal Bisnis Variabel Citra Perusahaan, Kepercayaan dan Biaya dan Manajemen, Vol. 7, No. 1, hal. 93-110.

Kismono, Gugup. 2001. Pengantar Bisnis, Edisi I, Cetakan I, Yogyakarta : BPFE.

Kotler, P. 2009. Manajemen pemasaran. Edisi 13. Jakarta : Erlangga.

Kotler,Philip, Kevin L. Keller 2012, Marketing Management. 13th edition, New Jersey : Pearson Prentice Hall, Inc.

Kotler, Philip. 2013, Marketting Management, 11th ed. Upper Saddle River, New Jersey : Prentice Hall, Inc.

Logiawan, Yenny dan Hartono Subagio. 2014. Analisa Customer Value terhadap Customer Loyalty dengan Customer Satisfaction sebagai Variabel Intervening pada Restoran Bandar Djakarta Surabaya. Jurnal Manajemen Pemasaran Petra. Vol.2 No. 1. 1-11

Lupiyoadi, Rambat; dan Hamdani, A. 2006. Manajemen Pemasaran Jasa Edisi Dua. Jakarta : Penerbit Salemba Empat.

Maharsi, 2016. Pengaruh Kepercayaan dan promosi Terhadap Loyalitas Pengguna Internet Banking di Surabaya melalui kepuasan pengguna. Jurnal Akuntansi Dan Keuangan, Vol. 8, NO. 1, MEI 2016: 35-5.

Madura, Jeff, 2001. Pengantar Bisnis, Introduction to Business, Alih Bahasa Saroyini W.R. Salib. Jakarta : Salemba Empat.

Nugroho, Agung. 2019. Membangun Loyalitas Konsumen pada Apotek Danusuman Surakarta. EJurnal STIE AUB Surakarta

Parasuraman, V., A. Zeithaml and L. L. Beny. 2013. A Conceptual Model of Service Quality and its Implication for Future Research. Journal of Marketing Research. 49. pp. 41-50

Pratiwi, ahmad Muhtadi dan Emma Surahman. 2016. Pengaruh Kualitas Pelayanan dan Kepuasan Pelanggan terhadap Niat Beli Obat di Depo Farmasi Anggrek RSUP Dr. Hasan Sadikin Bandung. Jurnal Farmasi Klinik Indonesia. Vo. 5 No. 1 P. 47-55.

Rahmawati, Rista Putri. 2017. Pengaruh Kualitas Pelayanan dan Promosi terhadap Loyalitas melalui Citra dan Kepuasan Pelanggan di Apotek Moro Sehat Desa Kedungmiri Kecamatan Mantingan Kabupaten Ngawi. E-Jurnal STIE AUB Surakarta.

Ramadhanta, 2016. Pengaruh Kualitas Pelayanan Terhadap Loyalitas Nasabah Dengan Kepuasan Dan Kepercayaan Nasabah Sebagai Variabel Intervening Pada PD Bank Jogja Yogyakarta. Jurnal Manajemen Bisnis Vol.2 No. 3 UNNES 
Saryono, 2009. Metodologi Penelitian Kesehatan Penuntun Praktis bagi Pemula. Yogyakarta : Mitra Cendika Press.

Selnes, 2013. An Examination of the Effect of Product Performance on Brand Reputation, Satisfaction and Loyalty. European Journal of Marketing. Vol.27, No. 9.

Sugiyono, 2014. Metodologi Penelitian Bisnis, Cetakan Keenam, Bandung : CV.Alfabeta.

Sugiyono, 2014, Metode Penelitian Kuantitatif Kualitatif dan R\&D, Cetakan ke , dua puluh Satu , Bandung : CV.Alfabeta.

Swastha, Basu dan Irawan H, 2012. Manajemen Pemasaran Modern, Yogayakarta : Liberty.

Tjiptono, Fandi. 2008, Manajemen Jasa, Yogyakarta : Penerbit Andi Offset

Tjiptono, Fandi. 2008, Prinsip-prinsip Total Quality Service, Yogyakarta : Penerbit Andi Offset

Tjiptono, Fandy. 2012. Manajemen Jasa. Malang: Bayu Media Publising

Tjiptono, Fandy and Gregorius Chandra. 2014, Service, Quality \& Satisfaction, Penerbit ANDI, Yogyakarta

Wang, I-Ming dan Shieh. Chich-Jen. 2016. The Relationship between Service Quality and Customer Satisfaction: The Example of CJCU Library. Journal of Information and Optimization Sciences, 27(1): h; 193-209

Zeithaml, Bitner and Gremler. 2006, Service Marketing, Fourth edition, Prentice Hall; exclusive right by Mc Graw-Hill.

Zuhri, Sarika, Andriansyah, Didi Asmadi dan Siti Khajar. 2010. Analisis Loyalitas Pelanggan Industri Jasa Pengiriman Menggunakan Strucural Equation Modeling. Jurnal Ilmiah Teknik Indistri. Vo.15 (2). 101-108

Peraturan Pemerintah Republik Indonesia Nomor 51 Tahun 2009 tentang Pekerjaan Kefarmasian. 